\title{
High Level of Resistance to nalidixic acid in Salmonella enterica serovar Typhi in Central India
}

\author{
Yashwant Kumar, Anshu Sharma and Kavaratty Raju Mani \\ National Salmonella and Escherichia Centre, Central Research Institute, Kasauli 173204, Himachal Pradesh, India
}

\begin{abstract}
Background: Fluoroquinolones are the drugs of choice for the treatment of typhoid fever. But the recent increase in minimum inhibitory concentration (MIC) values of ciprofloxacin in Salmonella Typhi may result in delayed response and serious complications. Nalidixic acid resistance has been used as an indirect evidence of increased minimum inhibitory concentration for ciprofloxacin in Salmonella Typhi.

Methods: We evaluated the isolates received at the National Salmonella and Escherichia Centre for nalidixic acid and ciprofloxacin susceptibility using standard methods. Minimum inhibitory concentrations have also been evaluated.

Results: Ninety-six percent of the isolates were found to be nalidixic acid resistant while all isolates were found to be ciprofloxacin sensitive. The difference between minimum inhibitory concentration values of ciprofloxacin for nalidixic acid resistant and nalidixic acid sensitive isolates was found to be statistically significant.

Conclusion: The study may be helpful in revising treatment strategies for the infections caused by nalidixic acid resistant Salmonella Typhi in the country.
\end{abstract}

Keywords: nalidixic acid, resistance, Salmonella Typhi, India

J Infect Dev Ctries 2009; 3(6):467-469.

Received 26 March 2009 - Accepted 29 May 2009

Copyright () 2009 Kumar et al. This is an open-access article distributed under the Creative Commons Attribution License, which permits unrestricted use, distribution, and reproduction in any medium, provided the original work is properly cited.

\section{Introduction}

Typhoid fever is a major health problem in developing countries such as India [1] and is also a potential threat to developed nations in an era of increasing immigration and global operation. Fluoroquinolones have been considered to be the empirical therapy of choice against MDR-ST [2]. However, towards the end of last decade, treatment failures with ciprofloxacin have been reported due to infection with nalidixic acid resistant Salmonella Typhi which were found to be susceptible to ciprofloxacin in disc diffusion tests. These strains exhibited a higher minimum inhibitory concentration (MIC) of ciprofloxacin [3]. The present study was undertaken to assess the nalidixic acid resistant strains of Salmonella Typhi circulating in the central west part of the country.

\section{Materials and Methods}

Fifty Salmonella Typhi isolates received from 14 hospitals of Maharashtra during the year 2008 at the National Salmonella and Escherichia Centre (National Reference Laboratory), Central Research Institute, Kasauli, India, constituted the material for the study. It should be noted that samples from different hospitals were not collected strictly in accordance with the protocol required for any epidemiological study.

Ready-made media and biochemicals (Hi Media Lab, Pvt. Ltd., Mumbai, India) were procured in their dehydrated form. All isolates were identified by conventional biochemical tests [4] and confirmed by serotyping [5] using standard Salmonella agglutinating sera (Seiken Laboratories, Tokyo, Japan). Antibiotic susceptibility patterns of the isolates were determined according to CLSI guidelines and interpretative criteria [6]. Minimum inhibitory concentrations were determined by agar dilution test [7] using purified antibiotic powders (Hi Media Laboratories, Pvt. Ltd., Mumbai, India).

\section{Results and Discussion}

Out of fifty isolates of Salmonella Typhi received at the National Salmonella and Escherichia Centre, $48(96 \%)$ were found to be resistant to nalidixic acid (NARST) with MIC values of $>480 \mathrm{mg} / \mathrm{L}$ and only 2 (4\%) isolates were found to be sensitive to nalidixic acid (NASST) with MIC values of $7.5 \mathrm{mg} / \mathrm{L}$ (Table 2). When these isolates were further tested against ciprofloxacin, all were found to be sensitive to 
Table 1. Details of the isolates.

\begin{tabular}{|c|c|c|c|}
\hline Period of isolation & Age of patients (yrs) & Place of isolation & Source \\
\hline January & $3-25$ & Maharashtra & Blood \\
\hline March & $5-22$ & Maharashtra & Blood \\
\hline April & $5-30$ & Maharashtra & Blood \\
\hline June & $10-25$ & Maharashtra & Blood \\
\hline August & $5-44$ & Maharashtra & Blood \\
\hline September & $1.5-26$ & Maharashtra & Maharashtra \\
\hline
\end{tabular}

* P-value $<0.05$ for NARST vs. NASST; compared by independent t test

ciprofloxacin with MIC values ranging between 0.029 and $0.625 \mathrm{mg} / \mathrm{L}$, which is considered to be in the susceptible range as per CLSI definition (susceptible if $\leq 1 \mu \mathrm{g} / \mathrm{ml}$ ) (Table 2).

The present study reports high frequency of NARST (96\%) (Table 2), which is higher in comparison to the earlier studies $(60-78 \%)[8,9,10]$ conducted in the country. No seasonal distribution has been found and the strains were found to be present throughout all seasons of the year (Table 1) depicting the risk of infections with these strains at any time. Almost every age group (Table 1) has been found to be infected with these strains.

The mean MIC of ciprofloxacin was found to be significantly higher for NARST as compared to that of NASST (Table 2, P $=0.0213$ ). In accordance with earlier studies [10], the sensitivity of nalidixic acid resistance as a surrogate marker for identifying isolates with increased levels of MIC of ciprofloxacin was found to be good in the present study.

However, non-typhoidal Salmonella strains have been reported from southeast Asia that are susceptible to nalidixic acid but show reduced susceptibility to ciprofloxacin [11]. This phenomenon occludes the use of nalidixic acid resistance determination by the disk diffusion method as a tool to screen for decreased ciprofloxacin susceptibility in non-typhoidal Salmonella. This resistance pattern may possibly be due to the presence of an efflux pump mechanism $[12,13]$ or mutations at locations other than gyrA [11]. Fluoroquinolone resistance in non-typhoidal Salmonella has emerged as a threat to the health community in the past few years $[14,15,16]$; therefore, invasive infections with serious complication caused by non-typhoidal Salmonella should be treated with increased caution to avoid treatment failures [17].

Association of nalidixic acid resistant Salmonella Typhi with severe clinical illness and treatment failures with fluoroquinolones is a matter of concern for the medical community and an alarming increase in the frequency of nalidixic acid resistance in Salmonella Typhi in the country aggravates the scenario. Use of ciprofloxacin may delay the initiation of appropriate antibiotic therapy and thereby may lead to increased morbidity due to very high frequency of NARST in the country.

\section{Conclusion}

The frequency of nalidixic acid resistance has been increasing for the past decade. In light of the endemicity of the disease and the prevalence of nalidixic acid resistant Salmonella Typhi in the country, health authorities should take appropriate steps to formulate therapeutic strategies.

Table 2. Antimicrobial susceptibility to nalidixic acid and ciprofloxacin.

\begin{tabular}{|c|c|c|}
\hline Antibiotic susceptibility & NARST & NASST \\
\hline Number of isolates & 48 & 2 \\
\hline Nalidixic acid MIC range $(\mathrm{mg} / \mathrm{L})$ & $>480$ & 7.5 \\
\hline Ciprofloxacin susceptibility & Sensitive & Sensitive \\
\hline Ciprofloxacin MIC range $(\mathrm{mg} / \mathrm{L})$ & $0.32 \pm 0.2^{*}$ & $0.019 \pm 0.0^{*}$ \\
\hline
\end{tabular}




\section{Acknowledgements}

The authors thank the heads of all the laboratories that referred Salmonella isolates to this centre. The technical assistance of Mr. Prem and Mr. Jagdish Kumar is also acknowledged. Thanks are due to Mr. Jiwa Ram for supplying media and biochemicals for biotyping.

\section{References}

1. Sinha A, Sazawal S, Kumar R, Sood S, Reddaiah VP, Singh B, Rao M, Naficy A, Clemens JD, Bhan MK. (1999) Typhoid fever in children aged less than 5 years. Lancet 354: 734-737.

2. Mermin JH, Townes JM, Gerber M, Dolan N, Mintz ED, Tauxe RV (1998) Typhoid fever in the United States, 19851994: Changing risks of international travel and increasing antimicrobial resistance. Arch Intern Med 158:633-638.

3. Wain J, Hoa NT, Chinh NT, Vinh H, Everett MJ, Diep TS, Day NPJ, Solomon T, White NJ, Piddock LJV, Parry CM. (1997) Quinolone-resistant Salmonella Typhi in Viet Nam: Molecular basis of resistance and clinical response to treatment. Clin Infect Dis 25: 1404-1410.

4. William RH (1994) Group 5: Facultative anaerobic Gram negative rods. In Bergey's Manual of Determinative Bacteriology. $9^{\text {th }} 270$ ed. Baltimore: Williams and Wilkins. 175-201.

5. Popoff MY, Le Minor L (1992) Antigenic formulas of the Salmonella serovars. 7th revision. WHO Collaborating Centre for Reference 264 Research on Salmonella. Paris: Institute Pasteur.

6. Wayne PA National Committee for Clinical Laboratory Standards (2000) National Committee for Clinical Laboratory Standards: Performance Standards for antimicrobial disc susceptibility tests, 7th ed. Approved standards M2-A6.

7. Wayne PA. Clinical and Laboratory Standards Institute (2006) Clinical and Laboratory Standards Institution: Methods for Dilution Antimicrobial Susceptibility Tests for Bacteria that Grow Aerobically. Approved standard, CLSI document M7-A7.

8. Rodrigues C, Mehta A, Joshi VR (1999) Nalidixic acidresistant Salmonella Typhi in Mumbai. Natl Med J India 12:88.

9. Kadhiravan T, Wig N, Kapil A, Kabra SK, Renuka K, Misra A (2005) Clinical outcomes in typhoid fever: adverse impact of infection with nalidixic acid-resistant Salmonella Typhi. BMC Infectious Diseases 5: 37.
10. Kapil A, Das B (2002) Nalidixic acid susceptibility to screen ciprofloxacin resistance in Salmonella Typhi. Indian J Med Res 115: 49-54.

11. Hakanen AJ, Lindgren M, Huovinen P, Jalava J, Siitonen A, Kotilainen P (2005) New Quinolone Resistance Phenomenon in Salmonella enterica: Nalidixic AcidSusceptible Isolates with Reduced Fluoroquinolone Susceptibility. J Clin Micro 43(11): 5775-5778.

12. Cebria'n L, Rodri'guez JC, Escribano I, Royo G (2005) Characterization of Salmonella spp. mutants with reduced fluoroquinolone susceptibility: Importance of efflux pump mechanisms. Chemotherapy 51: 40-43.

13. Piddock LJ, Jin YF, Webber MA, Everett MJ (2002) Novel ciprofloxacin-resistant, nalidixic acid-susceptible mutant of Staphylococcus aureus. Antimicrob. Ag. Chemother. 46: 2276-2278.

14. Malorny B, Schroeter A, Guerra B, Helmuth R (2003) Incidence of quinolone resistance in strains of Salmonella isolated from poultry, cattle and pigs in Germany between 1998 and 2001.Vet Rec 153: 643-8.

15. Sang-Ho C, Woo JH, Lee1 JE, Park SJ, Choo EJ, Kwak YG, Kim MN, Choi, MS, Lee NY, Lee BK, Kim NJ, Jeong JY, Ryu J, Kim YS (2005) Increasing incidence of quinolone resistance in human non-typhoid Salmonella enterica isolates in Korea and mechanisms involved in quinolone resistance. Journal of Antimicrobial Chemotherapy 56: 1111-1114.

16. Hakanen AJ, Kotilainen P, Pitka"nen S, Huikko S, Siitonen A, Huovinen P (2006) Reduction in fluoroquinolone susceptibility among non-typhoidal strains of Salmonella enterica isolated from Finnish patients. Journal of Antimicrobial Chemotherapy 57: 569-572.

17. Vasallo, FJ, Martin-Rabadan P, Alcala L, Garcia-Lechuz JM, Rodriguez-Creixems M, Bouza E (1998) Failure of ciprofloxacin therapy for invasive nontyphoidal salmonellosis. Clin Infect Dis 26: 535-536.

\section{Corresponding Author}

Yashwant Kumar

National Salmonella and Escherichia Centre

Central Research Institute

Kasauli (H.P) - 173204

Ph: +91-1792-272059 Ext. 218

E-mail: yasht26@yahoo.co.in

Conflict of interest: No conflict of interest is declared. 